\title{
Medical-legal and Social Premises Regarding the Individualization of Taking and Performing Medical Safety Measures Applicable to Both Psychiatric and Non-Psychiatric Patients
}

\section{Maria Marinela Mihaila}

Department of sociology and social work, University of laşi, Romania

"Corresponding author: Maria Marinela Mihaila, Department of sociology and social work, University of laşi, Romania, Tel: +40742096677; E-mail: sandum@uaic.ro Received date: January 25, 2018; Accepted date: January 31, 2018; Published date: February 08, 2018

Copyright: ( 2018 Mihaila MM, This is an open-access article distributed under the terms of the Creative Commons Attribution License, which permits unrestricted use, distribution, and reproduction in any medium, provided the original author and source are credited.

\begin{abstract}
The necessity of implementing of the project "Forensic Mental Healthcare FMH" in Romania regards the alignment of the internal legislation to the international and European standards regarding the psycho-social and juridical protection of the psychiatric patients, of the family, and the community, as well as the development of the institutional and community practices within the forensic psychiatric field in relation with the field of the social psychiatry. The scope of the FHM project in Romania regards the modifying and fulfilling of the existent legal frame along with the development of the institutional capacity on the principal of sustainability and of the public-private partnership. The feasibility of the project FMH is based on the pre-existence of certain models of social-juridical action the administration of the community sanctions correlated with the planning and the management of the sanctions and the custodial measures based on the streamlining of the costs of the medical-legal services and of those pre-existent psycho-social, which would lead to the implementing of a system of interlocking psycho-social and medical services within the psychiatric hospitals continued by special programs of surveillance and social rehabilitation, and taking the functional inter-institutional collaboration within the community as a leading principle.
\end{abstract}

Keywords: Forensic mental healthcare (FMH); Risk management; Medical-legal services; Surveillance and social rehabilitation

\section{Introduction}

The concept of "Forensic psychiatry" [1], respectively that of "Clinical forensic psychiatry" developed as "Overspecialization" for the first time in Great Britain in the 80s that would become major for all the European countries in the following years [2] correlated with that of "community/social psychiatry" [3] was brought to the attention of the Romanian researchers from an interdisciplinary perspective psychiatrists, legists, jurists, sociologists, psychologists, and social assistants along with the implementing and the development of European projects within the field. Even though the "forensic psychiatry" is defined mainly as a sub-species of general psychiatry [4], its practical relation to the field of the criminal law and criminal procedural law, which strongly connect to that of the criminal field which is oriented towards the sampling of material proves on the scene [5], as well as to that of the criminalistics, aggressive theory, victimology, and that of detentology [6] in regards to the revealing of the aetiology of the arising of the criminal behaviours. In this way, the Programme MATRA 2007-2008 [7] caused debates, conferences, and trainings of professional development based on the development of the professional identity along with the structuring and re-structuring of the institutions within the field of the clinical forensic psychiatry. Afterwards, the issue of the Forensic Mental Healthcare (FMH) raised major debates at the national level within the context of fighting for the rights of the patients suffering from mental disorders, under incidence of the safety measures having a medical character, and the round table with the title "The Obeying of the ONU Convention regarding the rights of the persons having certain psycho-social disabilities from theory to practice" that took place at the Palace of Parliament in
Bucharest on the 17th of May 2017. In order to allow for a comparison with the situation from other states which are members of the EU, the information within the Final Report Action plan MAT05/RM/9/4 [7] were compared with those within the research project initiated by the European Commission in 2005 [8], to which the scientific discoveries that guide the Romanian practice within the field of the clinical forensic psychiatry may be added.

\section{The Management of the risk of violence and the social responsibility from the perspective of Forensic Mental Healthcare (FMH)}

The researches within the field of criminology, the theory of aggressiveness, and victimology, applied to the medical-legal psychiatry correlate the concept of social responsibility with that of the danger of the wrong doer [9] by involving the paradigm of criminal desistance [10]. As it follows, the evaluating of the risk of relapse [11] by means of the development of certain standardized instruments for the evaluation of the potentially criminal needs and of the criminal risk is a priority for the present scientific research in our country, and it is supported by the results of the practical-applicative results based on the standardization of the evaluation of risks [12]. As the Final Report, Research Project Placement and Treatment of Mentally Ill Offenders Legislation and Practice in EU Members States [8] underlines, the main approaches for research in order to explore the relationship between the psychological disorders and the criminal risk regard the association between the predominance of the psychological or psychiatric disorders and the violent behaviour, even if the respective persons are or not in relation with the system of care for mental health or with the juridical system of civil or criminal law [13]. The hypothesis given for this course of thought suggest either the direct or the indirect causality in order to explain the possible connection 
between the psychiatric disorder and the violent conduct, or the etiological independence of the two phenomena [8].

In this way, the Programme MATRA 2007-2008 implemented the methodology of evaluating the risk of violence in the four high security mental hospitals in Romania; Sapoca (Buzău); Pădureni Grajduri (Iași); Ștei (Bihor); Jebel (Timiș) starting from the empirical research based on the clinical evaluation of the potentially aggressive factors, precisely the evaluating of the sexually violent behaviour. The results of the clinical analysis were correlated with the necessity of introducing of certain structured and standardized methods of evaluation and aggressiveness risk management, as it is the case of method HCR-20 and the instruments that are associated with it: SVR-20 and PCL-R/ PCL-SV [14], and as it followed it was to be adapted to the concrete situation of the patients of the four hospitals [7]. From the FMH perspective, the instruments of actuarial evaluation of the risk of relapse to which clinical estimations may be added contain specific indicators regarding the state of mental health that can be separately evaluated by means of some inventory for the certification of the psychotic character named "The inventory for the evaluation of psychosis" [15] adjusted after The Psychopathy Checklist Revised PCL$\mathrm{R}[16]$.

The modern etiological researches in the fields of criminology and the theory of aggressiveness continued the debates of the past century regarding the social responsibility correlated with criminal blame in the case of the persons suffering from mental disorders who commit crimes oscillating between the deterministic and the no deterministic (that of the freedom of choice) paradigms, and having consequences both on the reforms within the criminal legal system and on the those within the medical system, respectively the medical-legal one. The practical character of the researches in the field of clinical forensic psychiatry show that the efficacy of the programs of psycho-socialmedical treatment can be realized through an approach having a cognitive-behavioural and multi-modal character with an opening towards the community programs that offer a fixed medical-legal treatment, that is efficient in reducing the psychiatric symptoms and admonish against crime $[8,17]$.

As a result, the "Forensic care" the medical-legal treatment of the patients as a sub-species therapeutically oriented towards psychiatry but based on the psycho-social rehabilitation along with the stable medical-social treatment long term oriented, under the circumstances of public safety becomes a desideratum of all the community programs focus upon the forensic psychiatry [18], with an opening towards the social psychiatry. The importance of the factors that have a socialcultural character in the rehabilitation is brought to the attention of many researchers in the field of clinical psychiatry [19]. The issue associated with the psychiatric patients who commit crimes is a result of the fact that these persons are considered to be irresponsible at the moment of committing the crime and they are credited with "the unchargeable motives" [20]. This kind of approach influenced the social reactions, precisely the medical-legal practice in all the European countries, and the precarious health condition (morbidity), and not the needs having a potentially criminal character we underlined; In the meantime, the risk of relapse was neglected [21]. Moreover, researches in criminology showed in time that there is a direct relation of causality between the mental health condition and the criminal behaviour, and in this case the risk of committing crimes, respectively the risk of being aggressive is potentiated by the addictive behaviour [22]. In this way, the social reaction against the phenomenon of crime, especially the official reaction based on the conflict model can make a victim (and sometimes make a victim once more) out of the wrong doer and even of the whole system of social and familial relationships [23].

Although in the Western countries, the medical-legal psychiatry is considered to be a sub-specialty of general psychiatry, to the medical services offered to the persons suffering from mental disorders, that have a potential risk to commit crimes, an expertize within the field of the psycho-social evaluation of the psychiatric patients and the treatment of the associated chronical diseases that comport a risk for aggressive behaviour is added [24]. In this way, the specific character of the treatment within the forensic psychiatry resides in the complementarity and the simultaneous character of the medical treatment which is specific to the mental disease with the corrective treatment of a psycho-social character adjusted to the level of the risk of appearance of the aggressive behaviour correlated with the need of social rehabilitation [25]. From our point of view, considering the critic of the approaches that tend to "make crime be considered pathological in nature", the researches within the field of the forensic psychiatry have to remain focused on the preventive desistance, and this aspect is evident to the present crime law which defines "desisting and the impediment for the result to survene" by expressly referring to the crime desisting as a way of the attempt that does not brings the punishment of the author along in the case where the latter "renounced before the deed was discovered or announced the authorities about it being committed", and this having as a result the arresting or the suspending of the crime to be committed [20].

Also, the researches within the forensic psychiatry, combined with those within the field of clinical criminology cantered on the assessing and the management of the criminal risk offers an opening towards assisted desistance [26] "primary desistance" [27] in correlation with the "secondary desistance" or "the cognitive transformation theory" [28] by utilizing the significant differences among the different categories of vulnerable groups or of risk formed depending on the criteria of "age, sex, ethnicity" [29]. In this way, the psycho-medical assistation of the persons who commit crimes is based on plenty of theoretical models of the intervention which are limited by the biopathological, psychological, and sociological perspectives of criminology taking the paradigm risk-need-responsiveness, correlated with social responsibility, as a fundamental principle. As a conclusion, the criminology of development that is focus upon the researches within the field of "criminal career", which underlines the study of the wrong doer as "the main term for analyze", stirred a critical reaction about the research of the relapse of crime by proposing the approach of the phenomenon of relapse as a complex "social construction", having both a socio-economic and political character [29].

\section{Ethical-legal aspects in taking and putting the safety measures having a medical character into practice}

Medical Dictionary for the Health Professions and Nursing (2012) defines "Forensic Psychiatry" as being a way of applying psychiatry to criminal (and civil) law by underlining the causal determinants having a neuropsychiatric character when it comes to committing crime, which are established by means of medical-legal expertise as well as by any other experimental means, including those having a psycho-social character. In this way, the proving of one's sanity on the moment of initiating and producing the criminal act represents the "key moment" within the criminal trial that, either goes with the flow by initiating the criminal trial and obtaining the conviction, or exonerates the wrong doer from the responsibility of one's criminal deed, and he is 
considered outside the criminal justice system, as a psychiatric patient under the incidence of "the safety measures" provided by the current law as per art.110 of the Law no. 286/2009. According to The Romanian Criminal Law [20], the scope of the safety measures is represented by the "eliminating of a state of danger and the preventing of the committing of the crimes provisioned by the criminal law" [art. 107 line (1)], and these measures are being taken against the person who committed a deed unjustified as provisioned by the criminal law [art. 107 line (2)]. Also, the particular law referred to expressly considers the "categories of the safety measures", as it follows: "The obligation to medical treatment", "medical institutionalization", "the forbidding to have a certain position or to exercise a certain profession", "special sequestration" [art. 108 letter (a-d)]. Out of the above mentioned measures we shall consider in the following lines those having medical character, namely (art. 109 and art. 110) [20].

a. "The engagement to medical treatment" refers to the situation when the "wrong doer, because of some illness, including that caused by the chronical alcohol or other psychoactive drugs abuse, represents a social danger and can be obliged to follow some medical treatment until one's recovery or until amelioration that would surpass the danger" [art. 109 line (1)] next, the text of the criminal law distinguishes between two situations, namely: In the situation that "the person against which this measure was taken does not follow one's treatment medical institutionalization can be arranged" [art. 109 line (2)]; In the situation that "the person obliged to follow the treatment is convicted to a punishment depriving one of one's freedom, the treatment is to be followed even during the execution of punishment" [art. 109 line (3)].

b. "Medical institutionalization" regards the situation of the "wrong doer who is mentally ill, is a critical consumer of psychoactive drugs or suffers from an infectious and contagious disease and can be considered a danger to society", a situation when "there can be taken measures to hospitalize him in a specialized medical unity until one's recovery or amelioration that would set danger aside." (art. 110).

In this way, the law practice in Romania signals a series of ambiguities, some of which can be included within the category of the ethical dilemmas within the field of medical-legal psychiatry applied to FMH, namely: The prioritization of the applying of the safety measures within the stage previous to judgement or conviction against the applying of the same measures within the stage after the judgement or conviction or even execution; The issue of the limited discernment proved as a result of the medical-legal expertise that maintains the criminal responsibility and in this way the execution of the sentence to prison followed by the deterioration of one's mental and physical state, especially of the neuron-psychiatric symptomatology; The issue of the serial crimes when a crime is committed consciously and another without discerning; The issue of giving notice of the intermediary medical-legal expertise (realized in the course of putting the safety measures having a medical character into practice), correlated with the disaccord between the attitude of the psychiatric patient who asks for the measure to be ended and that of the designated judge designated who pronounces for the maintaining of the safety measure, to which we may add the obscurities about the procedural quality of the hospital unity; The applying of the safety measures "in the case that the wrong does is not punished at all" (art. 107 line (3) [20]; The issue of the "willingly" and that of the "unwillingly" hospitalization (Section 1, art. 50-53 and Section 2, art. 53-68 of the Law no. 487/2002) [30], the issue of temporary institutionalization etc.
Under the circumstances that certain situations that were previously presented are reported both to the physical and mental conditions of the person who committed the crime, as well as to the his/her sociojuridical condition, the necessity of individualizing the taking of the security measures having a medical character doubled by the necessity of planning when putting the safety measures into practice results, depending on the procedural quality of the wrong doer, namely: The individualization of the taking of the safety measures having a medical character within the stage before judgement (during the prosecution); The individualization of the taking of the safety measures having a medical character within the stage after judgment (after the final juridical definitive or no definitive sentence is pronounced); The planning of the applying of the safety measures having a medical character after the stage of the pronouncing of the sentence or during the execution of the sentence; The planning of the applying of the safety measures having a medical character in the situation that the wrong doer is not given a punishment.

In this way, the Final Report Programme MATRA shows that in Romania the law regarding the mental health condition legislation proving the mental health [30] made some amendments from the perspective of the European norms regarding the mental health, but the jurisprudence and the standards of the European Council still impose the changing of the law regarding the following aspects.

a. The legal character of the measure of institutionalization without consent or compulsory isolation and the complaint before the judges against this measure: Frequents procedural deadlines, the administration of the medical-legal evidence and legal representation in the situation that the decrease or lack of discernment is being noticed etc.

b. The character of the medical-legal proves regarding the persistence or the compensation or DE compensation of the mental disorder that would justify compulsory institutionalization and the extending of this measure, as it follows: The result of the mandatory medical control, the proving of the denial to be clinically examined, the regime of the medical-legal expertise associated with the psycho-social evaluations that would include an evaluation of the risk of aggressive/ violence behaviour (including the risk of self-injury) and the risk of being a public danger.

c. The legal character of the procedures of offering neuro-psychiatric medical assistance for people who commit serious crimes and who represent a high risk to be violent those persons who are imprisoned or are on remand and who suffer from a mental disorder or those persons who are the subjects of the measures of unwillingly medical institutionalization, as it follows: The special education of the medical personnel; The clear distinction between the therapy given to those suffering from mental disorders and that given to those presenting a disability; The rightening of the transfer of the persons suffering from mental disorders among the institutions/medical unities; The legal representing of the psychiatric patient and the consent of the patient's family or of his tutor aware of the situation; The regular controlling of the medical institutions by some independent forum etc.

Legal models and good practices at the European level within the FMH field

a. The international standards regarding the rights of the psychiatric patients are provisioned by the Convention on the rights of persons with disabilities whose general principles the respecting of the human 
dignity, no discrimination, the participation and social inclusion, tolerance, equality of chances, accessibility make reference to the "life standards and the adequate standards of social protection" both for the persons with disabilities and for their families "without making any discrimination and by considering the criteria of disability" (art. 28 of The Convention) [31].

b. The results of the implementing of European projects within the field of the forensic psychiatry, for example the project of research emitted by the European Commission and named: "Placement and Treatment of Mentally Ill Offenders Legislation and Practice in EU Members States", that shows the legal models and good practices of 15 states, members of the EU such as Austria, Belgium, Denmark, England and Wales, Finland, France, Germany, Greece, Ireland, Italy, Luxembourg, The Netherlands, Portugal, Spain, Sweden. The results of the present study delineate the legal circumstances associated with the procedures specific to the criminal procedure underlining the forensic psychiatric assessment and reassessment from the perspective of acknowledging the rights of the psychiatric patients, including the performing of psycho-social and medical services that are competent and no discriminatory. The study is realized by experts from the included member states and they are based on statistics and administrative data offered by the national ministries of health or/and of justice or by any other public authorities and it is surprising both regarding the general aspects, such as the balance between the public safety and the protection of the rights of the individual, as well as regarding the specific national aspects conferred by the legal frame by underlining either the legal system, or the medical system. In addition, as it is showed in Summary and Conclusions, the specific legislation of the forensic psychiatry is contained within a variety of criminal codes and special laws regarding health, respectively mental health, and these legal provisions are relatively new or adjusted within the past decade, which imposes as it follows the reviewing, the ameliorating, and the consolidation of the legal cadre at the national and European level [8].

c. The legislative models of some of the European countries imposed in time, and to them were added the good practices supported by an institutional development adequate to the needs of psycho-social and medical rehabilitation of the psychiatric patients that is brought under the incidence of the criminal law. In this way, we submit for attention the model offered by the Parliament of the Bavaria land which in 2015 brought under discussion a project of law regarding the "putting into practice of the measures of correction and safety, as well as of temporary commitment" known by the name of the Bavarian law regarding the institutionalization within the medical-legal psychiatric hospitals [32]

The field for applying the Bavarian law is represented by the procedure of hospitalization of some persons in psychiatric hospitals or in a rehab (psychiatric medical-legal hospital) based on a court decision (Title 1, Article 1). The execution of the measures of correction and safety (Title 2) expressly refers to the hospitalization and the planning of the treatment and of the associated disorders as well as to the plan of putting the measures into practice (Chapter 2 and 3). As it follows, the law provisions the diminishing of the punishment by probation, leaving the psychiatric hospital under guardianship, and bringing the checked to court (Chapter 4), the disciplinary and safety measures referring to the conditions of arrest, inquisition and investigation as well as the special measures of safety such as the measures of constraint having a medical character and the immobilization by using force (Chapter 5). Also, the Bavarian law refers to the financial help, the administration of the files of the patients and the protection of confidential data (Chapter 6 and 7), as well as to the maintaining of the premises of institutionalization (suspending or delaying the commitment) by including the conditions to be satisfied for discharge (Chapter 8).

The accomplishing of the procedure for institutionalization (Title 3) includes aspects referring to the leaving of the institution under surveillance, bringing the envisaged persons to court and the temporary transfer of the retained patient, as well as the passing from the temporary institutionalization to the institutionalization as such. The law also includes special provisions for certain vulnerable categories (Title 4) referring to pregnant women and the mothers of the newly born, the persons who have children to their care and the persons who are underage for this legal treatment. At the end of it, the law also contains provisions regarding the organization of the medicallegal hospitals and the specific costs of the hospitalization (Title 5).

Legal models and good practices at the national level within the FMH field

a. The programme MATRA 2007-2008 "Reforming of institutional and organisational structures of the high security mental hospitals in Romania" is very important to our country within the context of the public health policies in Romania compared to other European systems having as an immediate result the opening towards the ameliorating of the "circumstances" the social-juridical and economical context in realising the "medical-legal psychiatric care". Yet, as it could be observed on the occasion of defining the fields of inquiry of the domain of the medical-legal psychiatry, within the context of the Romanian general psychiatric system, the necessity to align with the "community acquis" has to be related to the legal and institutional specific to which the development of the "clinical forensic psychiatry" represents a real challenge at the national level. In this way, the MATRA Programme offers a perspective that is theoretically and empirically proved on the integrated practices from the level of the mental health system correlated with the system of criminal law focused on the development of a coherent system within the field of medical-legal psychiatry as a premise to the development of the Forensic Mental Healthcare (FMH) in Romania [7].

b. The National Health Strategy 2014-2020 elaborated by the Ministry of Health envisages the eliminating of the "weak" aspects of the sector of public health by referring to the "reducing of inequalities", "the optimising of the use of the resources of the health services" and the "promoting of the higher standards and of the good practices" based on the "needs of the individual and of the community". In this way, the proposals submitted, according to strategic plans, regard the following aspects [33]: The limiting according to region or the concentration of the medical specialized and institutionalized assistance and the making of regional chains of reference with hospitals and labs having various degrees of competency that are interconnected with the sector of primary and specialized home caring; The raise of the access to services of rehabilitation, medication and long term care; The corroboration among sectors for a better health condition of the people, especially for the vulnerable groups; The development of an adequate infrastructure at the national, regional and local level, regarding the diminishing of inequality regarding the access to health services.

c. The Strategy of the National Direction for Probation regarding the ways of executing the punishments without imprisonment (community sanctions) focused on the surveillance within the community and the psycho-social assistance of the convicted and the 
victims of certain types of crimes offer an alternative to custodial sanctions or those with imprisonment. In order to caution against the huge diversity of probation in terms of action firstly conferred by the "socio-juridical pluralism" of the sources/community resources [34] the European recommendations known under the name of The European Probation Rules [35] bring to attention certain values and principles that have to be respected in order to get to implement and develop a modern system of probation based on the paradigm of restorative justice and meanwhile assuring a set of unitary practices at the national and European level. These rules were imposed as ethicaljuridical standards within the larger field of handling the community measures and sanctions and implicitly within that of probation which assures the institutional frame for concretely putting it into practice at the local community level.

Within the Romanian system of criminal law, as part of the RomanGerman juridical system, the foundation of the community measures and punishments [36] is represented at present on the one hand, by the regime of the educational measures without imprisonment, and the obligations imposed by the court of law to the youngsters under the legal age (18) the internship for citizenship education; The surveillance of the minor; The resolution at the end of the week; Everyday (art. 117-123 of the Law no. 286/2009 in association article 69 letter (a-d) of the Law no. 252/2013) $[20,36]$ and on the other hand, the measures of surveillance and executing of the obligations established by the court for the major for whom it was decided that the execution of the punishment should be postponed, the execution of the punishment should be delayed, under surveillance, and liberation on probation (art. 83-106 of the Law no. 286/2009 to which art. 49 of the Law no. $252 / 2013$ was added) [20,36]; In addition to all these we may consider the paying of the fine by offering one's services without being paid to the benefit of the community (Chapter V, art. 104-106 of the Law no. 252/2013) [36].

The legal fundament of the development of the Romanian system of probation is consolidated by the evolution of the unitary practices supported at the national level through European projects that focus on the ethical-juridical approach [37]. The purposes of the actions that are specific to the Romanian system of probation are subordinated to the European frame conferred by the European Rules of Probation, regarding the realising of a dynamic equability among the diminishing of the risk of crime, the increasing of public safety, and the promoting of the community sanctions. Even if the protection and assistance of the victims of crime, provisioned by special laws is presently reglemented as a temporary action (art. 123 of the Law no. 252/2013) [36], the fact that probation represents nowadays a remarkable institutional resource and therefore a step forward towards the development of the activities of mediation in a larger meaning, respectively of those between the victim and its aggressor is to be noted.

d. The National strategy of social rehabilitation of those persons deprived of their freedom (2015-2019) [38] proposes a model of the progressive regimes of planning the execution of the punishment of confining to jail and the perspective of social rehabilitation of those deprived of their freedom, according with the suggestions of the European Council, which regard the politics or the penitentiary practice, in the first place, regarding education, health, and probation [39] etc. In this way, the perspective of modernizing criminal law in Romania regards both the development of the institution of probation and post penal programmes or "assistance for the social readmission within the community" which are specific to the stage of the criminal execution [40]. Therefore, The National Administration of the Penitentiaries (NAP) develop a strategy according to the executional and post-executional politics for implementing the concept of "social economy" that would allow attaining three major objectives, namely: The development of the institutional and inter-institutional capacity within the field of social rehabilitation of those deprived of their freedom and of those who carried their punishments out or were the subjects of other measured depriving them of their freedom; The development of educational programmes, of pedagogical assistance and social assistance during the detention and the informing of the public opinion; The facilitating of the after detention assistance at systemic level [38]. In this way, The Strategy [38] is based on a normative adequate frame the adopting of the new criminal codes and the modification of the special law according to those [41] as well as on a no discriminative practice realised through mechanisms and institutional procedures stressing upon the panning and the management of the punishment consisting in imprisonment, the education for freedom and the post penal assistance.

e. The planning and the management of the carrying out of the punishment represents a "continuous process of evaluation, planning, and re-evaluation of the punishment" [40] developed through complex activities that are realised within penitentiary unities by the specialized personnel in collaboration with the local structures for probation. The regimes of carrying out the punishments that are deprivative of liberty consist of a "series of rules" which are based on the "progressive and regressive systems", and those convicted pass from one regime to another, depending on their behaviour during detention (art. 30 line 1 and 2 of the Law 254/2013) [41]. A difference between the regime of carrying out of the punishments depriving of one's freedom-the regime of maximum security, the closed regime, the semi-open regime, and the open regime is made relatively to the degree of limiting the freedom of action of the convicted and by correlating this with the way of respecting their rights and of developing the activities, as well as depending on the conditions of detention (art. 31 line 1 and 2 of the Law 254/2013) [41].

f. The individualization of the regimes of carrying out the punishments depriving one of one's freedom is established according to the period of the detention, the behaviours, personality, the degree of risk, the age, the health condition, the identified needs and the possibilities of social rehabilitation of the convicted, all these being at the same time the criteria for involving the convicted person in educational, cultural, therapeutical, of guidance, social assistance, moral-religious, scholarly instructive, and regarding the vocational training activities (art. 41 line 1 and 2 of the Law 254/2013) [41]. The educational activities and the psychological assistance are realised in accordance with "The individualized plan of evaluation and educational and therapeutical intervention" which is made by specialists from the penitentiary with the participation depending on the situation of the councillors in probation, the volunteer, the associations and foundations, as well as of other representatives of the civil society depending on the risks and needs that were identified for each convicted person (art. 41 line 3 and 4 of the Law 254/2013) [41].

g. The preparedness for liberation and the post penal assistance is a complex process that starts even from the first day of detention along with the planning of the carrying out of the punishment and in this way defines the penal psycho-social assistance at the level of the penitentiary unities continued by the post penal assistance at the level of the services of probation, in collaboration with institutions and organizations within the field of social inclusion. A model of good 
practice within the field of reducing the risk of relapse and of social rehabilitation of the former convicted is offered by the programme for the "Reducing of the risk of relapse after imprisonment" that regards mainly the social rehabilitation of the personas who got out of jail on probation and in this way the specific activities for the education for freedom are supported [42]. The strategy NAP supports the implementation of this kind of programme by the fact that it associates within a recovering undertaking the educational activities, those of psychological assistance and of social assistance envisaged by the individualized plan for each individual deprived of one's freedom, by positively articulating them to the community resources: Social chains (circumstances or structures) of support; Social accommodations; Social inclusion centres; Structures of social economy [38] etc.

\section{Conclusion}

The purpose of the FMH project in Romania regards the amelioration of the mental health condition along with the reducing of the risk of aggressiveness/violence, as well as of the victim's behaviours, respectively that of self-victimization, when public safety is increased. As the Final Report of the Programme MATRA shows, coming to the same opinions regarding the harmonization of the legislation within the field of the forensic psychiatry along with the development of the institutional structures still represents a challenge but a premise as well for the development of the clinical forensic psychiatry and the proper functioning of the system Forensic Mental Healthcare (FMH) and of the juridical therein associated [7]. For this, the adopting of a special law regarding the taking and applying of the safety measures having a medical character, in accordance with the European recommendations and the internal legislation is necessary with high priority also, the building and the development of clinical medical-legal psychiatric hospitals for the applying of the safety measures having a medical character according to the European standards regarding the rehabilitation and social inclusion of the patients suffering from mental disorders.

\section{Conflict of interest}

The authors declare that they have no conflict of interest concerning this article.

\section{References}

1. Miller K, O'Toole MT (2003) Encyclopedia and dictionary of medicine, nursing and allied health. 7th edn, WB Saunders Company, Elsevier, Canada.

2. Eastman N, Adshead G, Fox S, Latham R, Whyte S (2012) Forensic psychiatry (Oxford specialist handbooks in psychiatry), Oxford University Press, Oxford, New York, USA.

3. Gordon H, Lindqvist P (2007) Forensic psychiatry in Europe. Psychiatric Bulletin 31: 421-424.

4. Howells K, Day A, Thomas PB (2004) Changing violent behaviour: Forensic mental health and criminological model compared. J Foren Psychiatr Psychol 15: 391-406.

5. Iacobuță AI (2002) Criminology. Junimea Publishing Press, Iasi, Romania.

6. Tănăsescu I (2003) Criminology. Agresologie, Victimology, Detentologie. All Beck Publishing Press, Bucharest, Romania.

7. MATRA project reforming of institutional and organizational structures of the high security mental hospitals in Romania (2008) Final reportAction plan MAT05/RM/9/4. Implementing risk assessment in the 4 high security mental hospitals in Romania. Bucharest, Romania.
8. European commission-health and consumer protection directorategeneral. Central institute of mental health, Final Report (2005) Mannheim, Germany.

9. Barras V, Bernheim J (1990) The history of law and psychiatry in Europe. Principles and practice of forensic psychiatry: 103-109.

10. McNeill $F$ (2006) A desistance paradigm for offender management. Criminol Crim Justice 6: 39-62.

11. Durnescu I (2002) The risk estimation of relapse. Handbook of social rehabilitation and surveillance counselor, Themis Publishing House, Craiova, Romania.

12. Webster C, MacDonald R, Simpson M (2006) Predicting criminality? risk factors, neighbourhood influence and desistance. Youth Justice. 6: 7-22.

13. Eronen M, Angermeyer M, Schulze B (1998) The psychiatric epidemiology of violent behaviour. Soc Psychiatry Psychiatr Epidemiol 33: S13-S23.

14. Hare RD, Black P, Walsh Z (2013) The PCL-R: Forensic applications and limitations. Forensic uses of clinical assessment instruments, Lawrence Erlbaum, Routledge, New York.

15. Durnescu I (2009) Social assistance in the penitentiary. Polirom Publishing House, Iasi, Romania.

16. Hare RD (1998) The hare PCL-R: Some issues concerning its use and misuse. Legal Criminol Psychol 3: 101-123.

17. Müller-Isberner R, Hodgins S (2000) Evidence-based treatment of mentally disordered offenders. Violence, crime and mentally disordered offenders, Wiley, Chichester, UK.

18. Mullen PE, Lindqvist $P$ (2000) Treatment and care in forensic mental health. New oxford textbook of psychiatry. Oxford University Press, Oxford.

19. Semple D, Smyth R (2013) Oxford handbook of psychiatry, 3rd edn. Oxford University Press, Oxford.

20. Law no. 286 of 2009 on the Romanian criminal code, with subsequent amendments. Romanian Official Gazette (2009).

21. Rylander G (1961) Forensic psychiatry in relation to legislation in different countries. An International Review. Springer 3: 397-451.

22. Goatly R (2002) Addiction and criminal behaviour. Handbook of social rehabilitation and surveillance counselor, Themis Publishing House, Craiova, Romania.

23. Boudon R (2006) Sociology treaty. Humanitas Publishing House, Bucharest, Romania.

24. Gunn J, Taylor P (2014) Forensic psychiatry: Clinical, legal and ethical issues. CRC Press Taylor \& Francis Group, London.

25. Andrews DA, Bonta JL (1995) The psychology of criminal conduct. Political Psychol 16: 657-659.

26. Weaver B, McNeill F (2007) Desistance, The dictionary of probation and offender management, Willan Publishing Cullompton, UK.

27. Maruna S, Farrall S (2004) Desistance from Crime: A theoretical reformulation. Kvlner Zetschrift fur Soziologie und Sozialpsychologie 43: 171-194.

28. Giordano PC, Cernkovich SA, Rudolph JL (2002) Gender, crime and desistance: Towards a theory of cognitive transformation. Am J Sociol 107: 990-1064.

29. Durnescu I, Lewis S, McNeill F, Raynor P, Vanstone M (2009) Reducing of the risk of relapse after imprisonment. Lumina Lex Publishing House, Bucharest, Romania.

30. Law no. 487 of 2002 on mental health and on protection the persons suffering from psychiatric disorders. Romanian official gazette (2002).

31. Convention on the rights of persons with disabilities and optional protocol to the convention (2007) open for signature at the united nations headquarters in New York.

32. Law no. $17 / 7478$ of 2015 on the execution of remedial and safety measures, as well as provisionally hospitalization. Bavarian law on hospitalization to forensic psychiatric clinics.

33. The National health strategy (2014-2020). 
Citation: Mihaila MM (2018) Medical-legal and Social Premises Regarding the Individualization of Taking and Performing Medical Safety Measures Applicable to Both Psychiatric and Non-Psychiatric Patients. J Forensic Res 9: 412. doi:10.4172/2157-7145.1000412

Page 7 of 7

34. Balahur D (2002) Socio-legal pluralism and the regulation of probation: Universal and European legislative standards. Handbook of social rehabilitation and surveillance counselor, Themis Publishing House, Craiova, Romania.

35. Recommendation no. R (92) 16 on European rules on community sanctions and measures (CSM).

36. Government decision no. 1079 of 2013 for the approval of the regulation on the application of the provisions of the law no. 252 of 2013 on the organization and functioning of the probation system. Official gazette (2014) Part I no. 5 January 7.

37. Mihăilă MM, Copoeru I (2013) Guide to solving ethical dilemmas in probation services. Ministry of Justice \& Konrad Adenauer Stiftung. Rule of law program south east Europe. Bucharest, Romania.

38. National strategy of social reintegration of those persons deprived of their Freedom (2015-2019) elaborated in accordance with the recommendations of the European union. Project ex-offenders community of practice. Berlin strategic forum (2012) on the unique strategy of social reintegration of people who have served custodial sentences.

39. Recommendation no. R (2003) 22 of the committee of ministers to member states on conditional release.

40. Durnescu I, Lazăr C (2002) The activity of the counselor for social rehabilitation and surveillance in the penitenciary. Handbook of social rehabilitation and surveillance counselor, Themis Publishing House, Craiova, Romania.

41. Law no. 254 of 2013 on the execution of punishments, educational measures and other non-custodial measures ordered by the court in the course of criminal trial, with subsequent amendments.

42. Poledna S, Sandu M, Berne AL, Foca L, Palaghia M (2009) Training manual on working with sentenced persons to be released from prison. Lumina Lex Publishing House, Buchareast, Romania. 